This article was published in Journal of Nanoparticle Research, 16 (4), 2368, 2014 http://dx.doi.org/10.1007/s11051-014-2368-4

\title{
Encapsulation of a proteasome inhibitor with gold-polyssacharide nanocarriers
}

Sílvia Castro Coelho ${ }^{1}$, Sandra Rocha ${ }^{2}$, Paula Sampaio ${ }^{3}$, Maria Carmo Pereira ${ }^{1}$, Manuel A.N. Coelho ${ }^{1, *}$

(1) LEPAE, Department of Chemical Engineering, Faculty of Engineering, University of Porto, Rua Roberto Frias, PT-4200-465 Porto, Portugal

(2) Department of Chemical and Biological Engineering, Chalmers University of Technology, Gothenburg SE-41296, Sweden

(3) Institute for Molecular Cell Biology (IBMC), Porto, Portugal

\author{
${ }^{*}$ Corresponding author: Manuel A. N. Coelho \\ e-mail: mcoelho@fe.up.pt.
}

\begin{abstract}
Designing positively charged chitosan-gum arabic-gold nanoparticle structures is farsighted to be a new approach to specific drug delivery. To reconnoitre this concept, an anticancer drug activity was evaluated with a proteasome inhibitor, bortezomib, in pancreatic cell lines, S2-013 and hTERT-HPNE. Laser scanning confocal microscopy show the uptake of the gold nanoparticle/bortezomib encapsulated in chitosan-gum arabic matrix and the fast internalization of these nanocombinations into pancreatic cells. Cytotoxic assays assessed that positively charged nanosystems reduce the cell growth and cell proliferation of S2-013s but the same effect was not observed in cytotoxic response in hTERT-HPNE cells. The findings of this study show the capacity of chitosan-gum arabic nanocarriers to deliver gold nanoparticles/anticancer drug and to increase the permeation and retention effect in S2-013 cells and minimize drug side effects in HPNE cells.
\end{abstract}

Keywords: gold nanoparticles, polyssacharides, cellular uptake, cancer cells

Introduction

Anticancer drugs have some limitations as low stability and half-life, bioavailability that can be minimized using nanoparticles (Iyer et al. 2006; Beija et al. 2012; Liu et al. 2012). Several studies showed that polymeric nanoparticles are suitable nanocarriers due to their high capacity of drug encapsulation and endocytosis efficiency by enhanced permeation and retention (EPR) effect (Garnett and Kallinteri 2006; Lee et al. 2013; Sinha et al. 2006). Also, it is reported that the circulation halftime of drugs is improved and protected from inactivity during blood circulation and transport to the specific tissue (Peres et al. 2012; Liu et al. 2012; Ruíz-Ramos et al. 2006; Goodarzi et al. 2013; Iyer et al. 2006; Nam et al. 2009; Yousefpour et al. 2011). Moreover, the nanoparticles are biocompatible, stable and in vitro non-toxic (Liu et al. 2008; Gomes et al. 2010). The control of charged surfaces allows interactions with negatively charged components from plasma membrane and, therefore, internalized into cells by endocytosis (Beija et al. 2012; Gratton et al. 2008). These acomplishments lead to improve drug delivery and to avoid undesirable systemic side-effects in normal surronding tissues (Kim et al. 2010; Choi et al. 2012). Chitosan $(\mathrm{Ch})$ is a cationic polyssacharide from the patial alkaline deacetylation of chitin (Ruíz-Ramos et al. 2006; Nitta and Numata 2013; Nam et al. 2009). It is a biodegradable and non-toxic polyssacharide that increases cell membrane permeability, used in biomedical applications (Liu et al. 2012; Goodarzi et al. 2013; Moschakis et al. 2010). Gum arabic (GA), approved by Food and Drug Administration, is an anionic polyssacharide by the exudates of acacia trees (Alvarez-Lorenzo et al. 2013; Moschakis et al. 2010). As a result, these polysacharides have several suitable characteristics to improve drug nanocarriers and enhance therapeutic efficacy.

Unique properties as biocompatibility, physical-chemical stability, namely high reactive surface, and nontoxicity make gold nanoparticles (AuNPs) eligible nanosystems for cancer treatment and diagnostics applications (Ghosh et al. 2008; Patra et al. 2010; Duncan et al. 2010; Parveen et al. 2012; Huang et al. 2011). Actually, AuNPs have been investigated for targeting drugs directly in situ, reducing several effects in the body, minimizing the multi-drug resistance (MRD) (Parveen et al. 2012). Also, AuNPs were chosen to accumulate in tumors through the EPR effect (Nitta and Numata 2013).

The presented investigation is focused on application of tumor targetting by a proteasome inhibitor, the bortezomib (BTZ), loaded in combination with pegylated gold nanoparticles (PEGAuNPs) into chitosangum arabic nanoparticles (Ch-GA NPs) to enhance anticancer drug activity and toxicity in cancer cells, 
protecting normal cells from the drug. Coelho et al. reported the BTZ surface adsorption to the PEGAuNPs led to a significant increase of BTZ toxicity with PEGAuNPs at low concentration levels (Coelho et al. 2013b). According to the cell uptake mechanism, a synergetic activity of the BTZ and AuNPs occurred. Therefore, the objective of the incorporation of bortezomib and pegylated gold nanoparticles into a positively charged chitosan-gum arabic matrix was to protect the systemic bioavailability of BTZ and avoid normal cells to be exposed to the toxicity of the drug. It was developed a technique to encapsulate PEGAuNPs combined with BTZ into Ch-GA NPs matrix by complex coacervation. There are electrostatic interactions of two polysacharides with opposite charged surface, in solution. This process is often used to encapsulate biomolecules and to control their release (Coelho et al. 2011; Moschakis et al. 2010).

BTZ is a dipeptide boronic acid, FDA-approved inhibitor of $26 \mathrm{~S}$ proteasome function, crucial to induce toxicity and apoptosis in tumor cells (Shahshahan et al. 2011). Some studies showed efficacy of bortezomib in treatment of several types of cancer namely pancreatic, lung and breast cancers (Shahshahan et al. 2011). The anticancer activity of the BTZ is expected to be enhanced by incorporation into the Ch-GA-PEGAuNPs but also to increase the systemic bioavailability of BTZ. The physicochemical properties and the in vitro cell uptake and cell growth of BTZ loaded Ch-GAPEGAuNPs nanoparticles were studied in the human pancreatic cancer cells, S2-013 and the immortalized human pancreatic duct epithelial cells, hTERT-HPNE, by laser scanning confocal microscopy (LSCM). S2-013 is a cloned subline of a pancreatic tumor cell line, SUIT-2, derived from a liver metastasis (Iwamura 1992; Tsutsumida et al. 2006). hTERT-HPNE, derived from the primary ducts of the adult pancreas, were transduced with an catalytic subunit of human telomerase (hTERT) (Lee et al. 2003).

Materials and methods

Materials

Chitosan $250 \mathrm{kDa}$ (degree of deacetylation $>93 \%$ ) was purchased from Altakitin (Portugal). Gum arabic (Mw 250,000, viscosity $60 \mathrm{mPa} \mathrm{s}$ ), dimethyl sulfoxide (DMSO), sulforhodamine B (SRB), trypan blue, trisodium citrate dihydrate and tetrachloroauric (III) acid ( $\mathrm{HAuCl}_{4} ; 99.99 \%$ trace metals basis, $30 \mathrm{wt} \%$ in dilute $\mathrm{HCl}$ ), glacial acetic acid, sodium hydroxide and sodium chloride were from Sigma-Aldrich (Germany).

Bortezomib (Velcade) was purchased from Selleck Chemicals LLC (USA); Fetal bovine serum (FBS), phosphate buffered saline (PBS), trypsin, Dulbecco's Modified Eagle medium (DMEM) and PrestoBlue ${ }^{\circledR}$ Cell Viability Reagent $(\mathrm{PB})$ were obtained from Invitrogen Co. (Scotland, UK). Tricloroacetic acid (TCA) and Tris buffer were acquired from Merck (Darmstadt, Germany). $\alpha$-thiol- $\omega$ carboxyl (polyethylene glycol) (HS-PEG-COOH; molecular weight $394.57 \mathrm{Da}$ ) was purchased from Prochimia (Poland).

Methods

Synthesis of pegylated gold nanoparticles

PEGAuNPs were prepared as previously described (Coelho et al. 2013a). The concentration of the PEGAuNPs was $18.9 \mathrm{nM}$ as determined by the Lambert-Beer Law assuming the molar absorptivity of the AuNPs plasmon resonance band at $526 \mathrm{~nm}$ being $2.33 \times 10^{8} \mathrm{M}^{-1} \mathrm{~cm}^{-1}$ (Baptista et al. 2005).

Preparation of chitosan-gum arabic nanoparticles

Solutions of the complexes were prepared with the initial concentrations of $\mathrm{Ch} 0.4 \%(\mathrm{w} / \mathrm{v})$ and $\mathrm{GA} / \mathrm{Ch}$ weight ratio $\left(\mathrm{R}_{\mathrm{GA} / \mathrm{Ch}}\right)$ of 1.2, according to the optimization previously described (Coelho et al. 2011). Briefly, Ch solutions were prepared by dissolving the mass in $1 \%$ aqueous acetic acid solution, followed by the $\mathrm{pH}$ adjustment to 4.8 , with $10 \%$ aqueous sodium hydroxide solution. GA was dissolved in ultrapure water. The complex preparation involved the mixture of aqueous phases of the two macromolecules, adding $3 \mathrm{~mL}$ of the correspondent GA solution to $3 \mathrm{~mL}$ of a Ch solution dropwise and under gentle magnetic stirring for 30 minutes at room temperature. The complexes $\mathrm{pH}$ was 4.8.

Preparation of PEGAuNPs loaded Ch-GA NPs

PEGAuNPs loaded complexes of chitosan-gum arabic were prepared in the same conditions of Ch-GA NPs. PEGAuNPs were added to the GA under magnetic stirring for 15 minutes at room temperature, followed by the adding of $\mathrm{Ch}$ solution dropwise for more 15 minutes. The initial concentrations of chitosan $0.4 \%(\mathrm{w} / \mathrm{v})$ and $\mathrm{GA} / \mathrm{Ch}$ weight ratio of 1.2. The final PEGAuNPs concentration into Ch-GAPEGAuNPs was $2 \mathrm{nM}$. The Ch-GA-PEGAuNPs $\mathrm{pH}$ was 4.7.

Preparation of BTZ loaded Ch-GA NPs (Ch-GA-BTZ NPs) 
A fresh BTZ solution was prepared in DMSO at room temperature and was added to GA solution, under homogenization for 15 minutes at room temperature. After, Ch solution was dropwise for more 15 minutes. The initial concentrations of chitosan $0.4 \%(\mathrm{w} / \mathrm{v})$ and $\mathrm{GA} / \mathrm{Ch}$ weight ratio of 1.2 . The final BTZ concentration was $200 \mathrm{nM}$. The Ch-GA-BTZ NPs pH was 4.8.

Preparation of Ch-GA NPs loaded with BTZ+PEGAuNPs (Ch-GA-BTZ+PEGAuNPs)

The mixture of BTZ and the PEGAuNPs was prepared by adding BTZ to PEGAuNPs solution to obtain the final PEGAuNPs and BTZ concentrations of 2.0 and $200.0 \mathrm{nM}$, respectively. Briefly, followed the preparation of the fresh BTZ+PEGAuNPs, GA solution was added, drop to drop room temperature. After 15 minutes of continuous mechanical stirring, $0.4 \%(\mathrm{w} / \mathrm{v})$ of initial concentration of Ch solution was added. Mechanical stirring was continued for 15 minutes. The Ch-GA-BTZ+PEGAuNPs pH was 4.6.

Dynamic light scattering (DLS) and electrophoretic mobility measurements

Size distribution and zeta potential of the suspensions were determined by DLS and laser doppler velocimetry, respectively, using a Zetasizer Nano ZS (Malvern Instruments Ltd., Malvern, UK), keeping the samples at $25^{\circ} \mathrm{C}$. Size measurements were performed at a scattering angle of $173^{\circ}$ in a $12 \mathrm{~mm}$ square polystyrene cuvette (Sarstedt, Germany). The zeta potential was obtained by using a disposable capillary cell (DTS 1060, Malvern).

Scanning electron microscopy (SEM)

SEM (JEOL JSM-6301F, Jeol Ltd., Tokyo, Japan) was used to study the morphological properties and to confirm the size measurements of PEGAuNPs.

Transmission electron microscopy (TEM)

$5 \mu \mathrm{L}$ of each sample was placed on carbon formvar-coated grid (Formvar/Carbon on 400 Mesh Copper from Agar Scientific, UK) and stained with 1\% (w/v) of filtered uranyl acetate solution. The grids were dried at room temperature and analyzed by transmission electron microscopy (TEM, Zeiss microscope operated at $60 \mathrm{kV})$.

UV-VIS spectroscopy

UV-Vis absorption measurements were carried out to confirm the BTZ and PEGAuNPs concentrations in the systems Ch-GA-PEGAuNPs, Ch-GA-BTZ NPs and Ch-GA-BTZ+PEGAuNPs, using a $1 \mathrm{~cm}$ quartz cuvette, at room temperature by Shimadzu UV-1700 PharmaSpec spectrophotometer.

In vitro drug release studies

BTZ release from the Ch-GA-BTZ NPs, Ch-GA-BTZ+PEGAuNPs was carried out, in vitro, at $37^{\circ} \mathrm{C}$ by dialysis. Dialysis was performed using a regenerated cellulose membrane, under constant magnetic stirring, with an initial BTZ concentration of $200 \mu \mathrm{M}$. The solutions were incubated in $6 \mathrm{~mL}$ of DI water and in PBS 0.01 M. The BTZ concentration of the dialysate buffer was analyzed with time using spectrophotometric analysis at $270 \mathrm{~nm}$. The BTZ concentration released was calculated from the standard calibration curves of BTZ solution in DI water and in PBS $0.01 \mathrm{M}$.

Cell culture

Human pancreatic cancer cell line (S2-013) and immortalized human pancreatic duct epithelial cells (hTERT-HPNE) were provided by Prof. M. A. Hollingsworth (UNNC - Omaha, USA). hTERT-HPNE were found to be free of cancer-associated changes or altering phenotypic properties. This type of cells was highly homogeneous for this phenotype with no evidence of ductal epithelial cells still remaining, indicating that our culture conditions were ideal for the selection and expansion of this rare cell type and should have helpful for a better define the biological role of this novel cell type (Lee et al. 2003). The cells were maintained in DMEM medium, supplemented with 10\% FBS under 5\% $\mathrm{CO}_{2}$ humidified atmosphere at 37 ${ }^{\circ} \mathrm{C}$.

In vitro cell uptake study

Imaging experiments were performed with the S2-013 and hTERT-HPNE to examine the uptake of ChGA-BTZ+PEGAuNPs. Briefly, pancreatic cells were seeded on a $\mu$-chamber 12 -well plates (ibidi, Germany) 800 cells/well in under normal conditions $\left(5 \% \mathrm{CO}_{2}\right.$ humidified atmosphere at $\left.37{ }^{\circ} \mathrm{C}\right)$ for attachment. After 24hours of attachment, the cells were treated with a constant BTZ concentration (100 $\mathrm{nM}$ ) of BTZ loaded Ch-GA-PEGAuNPs for 48 hours. After the incubation, the cells were rinsed with $1 \%$ of phosphate buffered saline (PBS) solution, to eliminate the Ch-GA-BTZ+PEGAuNPs, and fixated using $4 \%$ paraformaldehyde for 15 minutes. The cells were washed with PBS and mounted in a glycerol-based 
non-drying and non-hardening medium. Imaging was performed by confocal imaging technique using a laser scanning confocal microscope (LSCM) TCS SP5 II (Leica Microsystems, Germany), in reflectance and transmittance mode (Joo et al. 2010; Taylor et al. 2010). To evaluate the nanoparticle internalization in the cells, the control untreated cells were also imaged. Different areas were analysed and at least three images were acquired for each type of cell. Cell imaging showed reproducible results.

In vitro cytotoxicity study

In vitro cytotoxicity of BTZ, Ch-GA NPs, Ch-GA-BTZ NPs, Ch-GA-PEGAuNPs and Ch-GA-

BTZ+PEGAuNPs against pancreatic cell lines was evaluated by two different assays based on PrestoBlue (PB) (fluorescence) and Sulforhodamine B (SRB) (colorimetric) (Coelho et al. 2013a). Both assays allow an indirect estimation of viable cell number: the PB assay by the metabolization of resazurin to resofurin, and the SRB assay by staining cellular proteins with the dye SRB (Vichai and Kirtikara 2006; Skehan et al. 1990). Briefly, the S2-013 and hTERT-HPNE cells were seeded on 96-well plates with a cell density at 1000 cells per well, under normal conditions $\left(5 \% \mathrm{CO}_{2}\right.$ humidified atmosphere at $\left.37^{\circ} \mathrm{C}\right)$ and allowed to adhere for 24 hours. Then, the cells were treated for 48 hours with BTZ, Ch-GA-BTZ NPs and Ch-GA$\mathrm{BTZ}+\mathrm{PEGAuNPs}$ at the concentrations ranging between 0.01 and $100 \mathrm{nM} \mathrm{BTZ}$; and Ch-GA NPs and ChGA-PEGAuNPs at the concentrations ranging between $1.1 \times 10^{-7}$ to $3.3 \times 10^{-3} \mathrm{mg} / \mathrm{mL}$. Thereafter, $50 \mu \mathrm{L}$ of PB reagent (diluted 1:10 in the DMEM medium) were added to each well and incubated for 45 minutes at $37^{\circ} \mathrm{C}$. The PB reagent is modified by the reducing environment of the viable cells turning into red color and becoming fluorescent. Finally, the fluorescence was measured using a microplate reader (PowerWave HT Microplate Spectrophotometer, BioTek) at an excitation and emission wavelengths of 560 and 590 nm, respectively.

For the SRB assay, the cells were fixated with $10 \%$ TCA for 1 hour on ice. After the incubation period the cell monolayers were washed and stained with $50 \mu \mathrm{L}$ SRB dye for 30 minutes. The cells were then washed repeatedly with $1 \%$ acetic acid to remove unbound dye. The cells were dried and the proteinbound stain was solubilised with $10 \mathrm{mM}$ Tris solution. The SRB absorbance was measured at $560 \mathrm{~nm}$ using the PowerWave microplate reader (Skehan et al. 1990). Concentration for 50\% growth inhibition $\left(\mathrm{GI}_{50}\right)$ was evaluated from the SRB assay. The absorbance of the wells containing the nanoparticles or drug and the absorbance of the wells containing untreated cells following a 48 hours incubation period were subsequently compared with that of the wells containing the cells that have been fixated at time zero (when the nanoparticles and drug were added) (Monks et al. 1991; Coelho et al. 2013a).

For each assay, three independent experiments were measured in triplicate. Statistical significance $(\mathrm{p}<$ 0.05 ) was determined by the Student's t-Test.

Results and discussion

The Ch-GA based nanoparticles alone and loaded with pegylated gold nanoparticles and BTZ were prepared through a coacervation process. Figure $1 \mathrm{a}$ and Figure $1 \mathrm{~b}$ confirmed the presence of PEGAuNPs inside of the complexes without and with BTZ, respectively. The Ch-GA-BTZ+PEGAuNPs show two typical absorption bands centered at 528.5 and $268.5 \mathrm{~nm}$ from PEGAuNPs and BTZ, respectively (data not shown). These nanosystems were stable for several weeks stored at $4^{\circ} \mathrm{C}$ in the dark. DLS measurements were in agreement with the TEM analysis, and are shown in Table 1. The average hydrodynamic diameter of Ch-GA NPs ranged from $315 \mathrm{~nm}$ to $327 \mathrm{~nm}$ (loaded with PEGAuNPs) and the polydispersity index (PdI) was 0.3 . This diameter change occurs due to the presence of spherical PEGAuNPs with small diameters ( $39 \mathrm{~nm}$ ), as depicted in Online Resource 1. In BTZ loaded Ch-GAPEGAuNPs, no significant change in the nanoparticle diameter was observed.

The zeta potential of the mixture BTZ+PEGAuNPs was $-13 \pm 2 \mathrm{mV}$ in water. This value is significantly different from PEGAuNPs $(-39 \pm 3 \mathrm{mV})$, suggesting a strong adsorption of BTZ on the PEGAuNPs surface (Coelho et al. 2013b). The average zeta potential was positive for the different nanosystem formulations, which is attributed to the residual amine groups of $\mathrm{Ch}$ that neutralize the negative charges of GA and PEGAuNPs. Also, the strong positive charges on the surface of nanoparticles prevent the aggregation (Table 1) (Wang et al. 2008; Avadi et al. 2010; Avadi et al. 2011).

The release profiles of BTZ from Ch-GA NPs and Ch-GA-PEGAuNPs were performed in vitro using a dialysis membrane in PBS $0.01 \mathrm{M}$ at $37^{\circ} \mathrm{C}$. The results are depicted in Figure 2. In PBS (pH 7.0), the BTZ release profile is limited by the release of the PEGAuNPs from the polysaccharide matrix explained by the delay of 5 hours. At the same conditions, the release of BTZ from PEGAuNPs has also a gap of about 2 hours (Coelho et al. 2013b). For these systems, the BTZ released after 10 hours was $85 \%$. Also, PBS provides an effect on BTZ adsorption of Ch-GA-BTZ NPs and Ch-GA-BTZ+PEGAuNPs systems, slowing down the $\mathrm{BTZ}$ release in the last nanoparticles.

The cellular uptake of Ch-GA-BTZ+PEGAuNPs with BTZ concentration of $100 \mathrm{nM}$ in pancreatic cells (S2-013) and immortalized human pancreatic duct epithelial cells (hTERT-HPNE) was investigated by 
confocal microscopy. From our observations we can conclude that PEGAuNPs were internalized and distributed throughout S2-013 and hTERT-HPNE cells after 48 hours incubation, as illustrated in Figure $3 \mathrm{c}$ and Figure $3 \mathrm{~d}$.

The detection of PEGAuNPs associated to the light scattering by LSCM leads to a clear distinction between PEGAUNPs containing cells and the negative controls. It was observed that the accumulation of the nanoparticles into the cytoplasm effectively improve the cytotoxicity in both cell lines.

The in vitro cytotoxicity studies of the effects of Ch-GA-PEGAuNPs, Ch-GA NPs, BTZ alone, Ch-GABTZ+PEGAuNPs and Ch-GA-BTZ NPs were performed with S2-013 and hTERT-HPNE. The cells were exposed to a range of experimental concentration of BTZ loaded nanoparticles and blank nanoparticles for 48 hours at $37^{\circ} \mathrm{C}$. Their effect was evaluated by SRB and PB methods. Ch-GA-PEGAuNPs and ChGA NPs with Ch concentration up to $3.3 \times 10^{-3} \mathrm{mg} / \mathrm{mL}$ and $\mathrm{R}_{\mathrm{GA} / \mathrm{Ch}}$ of 1.2 do not show any cytotoxicity on both cell lines (Figure 4), showing good biocompatibility. The inhibitory effect of BTZ on proliferation of S2-013 and hTERT-HPNE was evaluated on Ch-GA-BTZ+PEGAuNPs and Ch-GA-BTZ NPs. The effect of BTZ at concentrations from 0.1 to $100.0 \mathrm{nM}$ was tested in these two systems with concentrations of $\mathrm{Ch}$ in the range $1.1 \times 10^{-7}$ to $3.3 \times 10^{-3} \mathrm{mg} / \mathrm{mL}$ and $\mathrm{R}_{\mathrm{GA} / \mathrm{Ch}}$ of 1.2 (Figure 5). As presented in Figure $5 \mathrm{a}$ and Figure 5c, BTZ loaded Ch-GA NPs and BTZ loaded Ch-GA-PEGAuNPs decrease the growth rate of the S2-013 cells, when compared with BTZ alone, especially to 1.0 and to $10.0 \mathrm{nM}$ of BTZ concentration. A possible reason for the efficacy increase of cytotoxicity of BTZ is the efficient delivery by the nanoparticles. Ch-GA system might augment protection of BTZ. Also for $10.0 \mathrm{nM}$ BTZ loaded in Ch-GA NPs and loaded in Ch-GA-PEGAuNPs reduced the cell growth to about $13 \%$ compared with $58 \%$ to BTZ alone. This suggests that Ch-GA nanosystem efficacy might improve in vivo through the EPR effect (Nam et al. 2009). Moreover, at this concentration range Ch-GA-BTZ+PEGAuNPs does not show toxicity to hTERT-HPNEs (Figure 5d).

In Table 2, the $\mathrm{GI}_{50}$ concentration (obtained by SRB assay) is the BTZ concentration corresponding to $50 \%$ of the highest inhibition on cell proliferation. In S2-013 cells, this value is lower to Ch-GABTZ+PEGAuNPs $(0.20 \mathrm{nM})$ and Ch-GA-BTZ NPs $(0.12 \mathrm{nM})$ when compared to BTZ alone $(1.70 \mathrm{nM})(p$ $<0.05)$. Also, Ch-GA-BTZ+PEGAuNPs is more pronounced on inducing cell death than BTZ alone for drug concentrations over $1.0 \mathrm{nM}$. In hTERT-HPNEne cells an oppositive effect is observed, BTZ alone is significantly $(\mathrm{p}<0.05)$ more effective, decreasing cell survival, and presents an inhibitory effect on cell growth, at concentrations of 2nM (Table 2). Moreover, Figure 6 the percent growth is defined by the difference between viable cell and initial cell number divided by initial cell number. For values above zero, it is expected that the cells are inhibited but are not death. For values below zero, it is considered cell death. These data were achieved by following SRB assay. It is shown that BTZ loaded nanoparticles decrease significantly the S2-013 cell growth rate when compared to BTZ alone. Also, it is showed that in hTERT-HPNEs the same effect is not observed. In fact, hTERT-HPNE cell growth did not change with BTZ loaded nanoparticles in the range concentration of 0.1 and $100.0 \mathrm{nM}$ (Figure 6b). This could be explained by the effect of carbohydrate matrix on the BTZ release in normal cells.

Conclusion

It was developed a novel chitosan-gum arabic-gold nanoparticle system with positively charged for the delivery of the proteasome inhibitor, bortezomib. BTZ was entrapped into the polyssacharides-gold nanoparticles system. Confocal images indicate that Ch-GA-BTZ+PEGAuNPs were internalized by the pancreatic cells through endocytic mechanism and are able to enhance permeation and retention of BTZ activity. There is a decreasing in the required drug concentration to induce cell proliferation. The in vitro cytotoxic study revealed that $10.0 \mathrm{nM}$ BTZ loaded Ch-GA-PEGAuNPs had a significant toxicity to human pancreatic cancer cells as compared to the drug alone. Also, at the same BTZ concentration, the nanosystem has no toxic effect to immortalized human pancreatic duct epithelial cells, suggesting that these nanoparticles can have good applicability to overcome limitations associated to low bioavailability, in situ delivery and decrease side effects.

Nonetheless the potential application in cancer therapy, the nanoparticles developed can be further explored for clinical diagnosis. Its utility can be enhanced by application of fluorescently tagged, biomarker-targeted nanoparticles to provide selective, specific contrast-rich imaging to maximize the security of the diagnosis. As an example it can be used as a diagnostic tool for clinical application in fluorescence endoscopy, specifically targeted for biomarker molecules characteristic of the adenocarcinomatous pathophysiological state.

Acknowledgement

We gratefully acknowledge FCT-projects (PTDC/QUI-BIQ/115449/2009) and COMPETE/QREN/UEproject (NORTE-07-0162-FEDER-000033) by the funding received. 
We gratefully acknowledge Prof. Michael A. Hollingsworth (University of Nebraska Medical Center Omaha, USA) for kindly providing the human pancreatic cell lines (S2-013 and hTERT-HPNE).

References

Alvarez-Lorenzo C, Blanco-Fernandez B, Puga AM, Concheiro A (2013) Crosslinked ionic polysaccharides for stimuli-sensitive drug delivery. Adv Drug Deliv Rev 29 (13):00101-00104

Avadi MR, Sadeghi AMM, Mohamadpour Dounighi N, Dinarvand R, Atyabi F, Rafiee-Tehrani M (2011) Ex vivo evaluation of insulin nanoparticles using chitosan and arabic gum, vol 2011.

Avadi MR, Sadeghi AMM, Mohammadpour N, Abedin S, Atyabi F, Dinarvand R, Rafiee-Tehrani M (2010) Preparation and characterization of insulin nanoparticles using chitosan and Arabic gum with ionic gelation method. Nanomedicine : nanotechnology, biology, and medicine 6 (1):58-63

Baptista P, Doria G, Henriques D, Pereira E, Franco R (2005) Colorimetric detection of eukaryotic gene expression with DNA-derivatized gold nanoparticles. J Biotechnol 119 (2):111-117

Beija M, Salvayre R, Lauth-de Viguerie N, Marty J-D (2012) Colloidal systems for drug delivery: from design to therapy. Trends in Biotechnology 30 (9):485-496. doi:http://dx.doi.org/10.1016/j.tibtech.2012.04.008

Choi S, Jang S, Park J, Jeong S, Park J, Ock K, Lee K, Yang S, Joo S-W, Ryu P, Lee S (2012) Cellular uptake and cytotoxicity of positively charged chitosan gold nanoparticles in human lung adenocarcinoma cells. J Nanopart Res 14 (12):1-13. doi:10.1007/s11051-012-1234-5

Coelho S, Moreno-Flores S, Toca-Herrera JL, Coelho MAN, Carmo Pereira M, Rocha S (2011) Nanostructure of polysaccharide complexes. Journal of Colloid and Interface Science 363 (2):450455. doi:http://dx.doi.org/10.1016/j.jcis.2011.07.098

Coelho SC, Rocha S, Juzenas P, Sampaio P, Almeida GM, Silva FS, Pereira MC, Coelho MA (2013a) Gold nanoparticle delivery-enhanced proteasome inhibitor effect in adenocarcinoma cells. Expert Opin Drug Deliv 13:13

Coelho SC, Rocha S, Juzenas P, Sampaio P, Almeida GM, Silva FS, Pereira MC, Coelho MAN (2013b) Gold nanoparticle delivery-enhanced proteasome inhibitor effect in adenocarcinoma cells. Expert Opinion on Drug Delivery 10 (10):1345-1352. doi:doi:10.1517/17425247.2013.827659

Duncan B, Kim C, Rotello VM (2010) Gold nanoparticle platforms as drug and biomacromolecule delivery $\begin{array}{llllll}\text { systems. Journal of } & \text { Controlled } & \text { Release } & 148 & \text { (1):122-127. }\end{array}$ doi:http://dx.doi.org/10.1016/j.jconrel.2010.06.004

Garnett MC, Kallinteri P (2006) Nanomedicines and nanotoxicology: some physiological principles. Occupational Medicine 56 (5):307-311. doi:10.1093/occmed/kq1052

Ghosh P, Han G, De M, Kim CK, Rotello VM (2008) Gold nanoparticles in delivery applications. Advanced Drug Delivery Reviews 60 (11):1307-1315. doi:10.1016/j.addr.2008.03.016

Gomes JF, Rocha S, do Carmo Pereira M, Peres I, Moreno S, Toca-Herrera J, Coelho MA (2010) Lipid/particle assemblies based on maltodextrin-gum arabic core as bio-carriers. Colloids Surf B Biointerfaces 76 (2):449-455

Goodarzi N, Varshochian R, Kamalinia G, Atyabi F, Dinarvand R (2013) A review of polysaccharide cytotoxic drug conjugates for cancer therapy. Carbohydrate Polymers 92 (2):1280-1293. doi:http://dx.doi.org/10.1016/j.carbpol.2012.10.036

Gratton SEA, Ropp PA, Pohlhaus PD, Luft JC, Madden VJ, Napier ME, DeSimone JM (2008) The effect of particle design on cellular internalization pathways. Proceedings of the National Academy of Sciences 105 (33):11613-11618. doi:10.1073/pnas.0801763105

Huang H-C, Barua S, Sharma G, Dey SK, Rege K (2011) Inorganic nanoparticles for cancer imaging and $\begin{array}{lllll}\text { therapy. Journal of } & \text { Controlled } & \text { Release } & & \end{array}$ doi:http://dx.doi.org/10.1016/j.jconrel.2011.06.004

Iwamura $\mathrm{T}$ (1992) Correlation between CA19-9 production in vitro and histological grades of differentiation in vivo in clones isolated from a human pancreatic cancer cell line (SUIT-2). Gastroenterol Hepatol (7):512-519

Iyer AK, Khaled G, Fang J, Maeda H (2006) Exploiting the enhanced permeability and retention effect for tumor targeting. Drug Discovery Today $11 \quad$ (17-18):812-818. doi:http://dx.doi.org/10.1016/j.drudis.2006.07.005

Joo C, Zhan C, Li Q, Yazdanfar S (2010) Autoconfocal transmission microscopy based on two-photoninduced photocurrent of Si photodiodes. Opt Lett 35 (1):67-69

Kim B, Han G, Toley BJ, Kim CK, Rotello VM, Forbes NS (2010) Tuning payload delivery in tumour cylindroids using gold nanoparticles. Nat Nanotechnol 5 (6):465-472

Lee J, Twomey M, Machado C, Gomez G, Doshi M, Gesquiere AJ, Moon JH (2013) Caveolae-mediated endocytosis of conjugated polymer nanoparticles. Macromol Biosci 13 (7):913-920 
Lee KM, Nguyen C, Ulrich AB, Pour PM, Ouellette MM (2003) Immortalization with telomerase of the Nestin-positive cells of the human pancreas. Biochem Biophys Res Commun 301 (4):1038-1044

Liu J, Xu L, Liu C, Zhang D, Wang S, Deng Z, Lou W, Xu H, Bai Q, Ma J (2012) Preparation and characterization of cationic curcumin nanoparticles for improvement of cellular uptake. Carbohydrate Polymers 90 (1):16-22. doi:http://dx.doi.org/10.1016/j.carbpol.2012.04.036

Liu Z, Jiao Y, Wang Y, Zhou C, Zhang Z (2008) Polysaccharides-based nanoparticles as drug delivery systems. Advanced Drug Delivery Reviews 60 (15):1650-1662. doi:10.1016/j.addr.2008.09.001

Monks A, Scudiero D, Skehan P, Shoemaker R, Paull K, Vistica D, Hose C, Langley J, Cronise P, VaigroWolff A, Gray-Goodrich M, Campbell H, Mayo J, Boyd M (1991) Feasibility of a High-Flux Anticancer Drug Screen Using a Diverse Panel of Cultured Human Tumor Cell Lines. Journal of the National Cancer Institute 83 (11):757-766. doi:10.1093/jnci/83.11.757

Moschakis T, Murray BS, Biliaderis CG (2010) Modifications in stability and structure of whey proteincoated $\mathrm{o} / \mathrm{w}$ emulsions by interacting chitosan and gum arabic mixed dispersions. Food Hydrocolloids 24 (1):8-17. doi:10.1016/j.foodhyd.2009.07.001

Nam HY, Kwon SM, Chung H, Lee SY, Kwon SH, Jeon H, Kim Y, Park JH, Kim J, Her S, Oh YK, Kwon IC, Kim K, Jeong SY (2009) Cellular uptake mechanism and intracellular fate of hydrophobically modified glycol chitosan nanoparticles. J Control Release 135 (3):259-267

Nitta S, Numata K (2013) Biopolymer-Based Nanoparticles for Drug/Gene Delivery and Tissue Engineering. International Journal of Molecular Sciences 14 (1):1629-1654

Parveen S, Misra R, Sahoo SK (2012) Nanoparticles: a boon to drug delivery, therapeutics, diagnostics and imaging. Nanomedicine 8 (2):147-166

Patra CR, Bhattacharya R, Mukhopadhyay D, Mukherjee P (2010) Fabrication of gold nanoparticles for targeted therapy in pancreatic cancer. Advanced Drug Delivery Reviews 62 (3):346-361. doi:DOI: 10.1016/j.addr.2009.11.007

Peres I, Rocha S, Loureiro J, Carmo Pereira M, Ivanova G, Coelho M (2012) Carbohydrate particles as protein carriers and scaffolds: physico-chemical characterization and collagen stability. J Nanopart Res 14 (9):1-11. doi:10.1007/s11051-012-1144-6

Ruíz-Ramos JO, Pérez-Orozco JP, Báez-González JG, Bósquez-Molina E, Pérez-Alonso C, Vernon-Carter EJ (2006) Interrelationship between the viscoelastic properties and effective moisture diffusivity of emulsions with the water vapor permeability of edible films stabilized by mesquite gum-

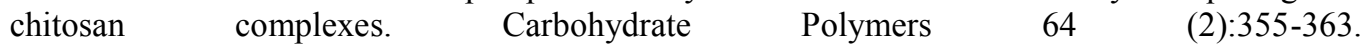
doi:http://dx.doi.org/10.1016/j.carbpol.2005.12.020

Shahshahan MA, Beckley MN, Jazirehi AR (2011) Potential usage of proteasome inhibitor bortezomib (Velcade, PS-341) in the treatment of metastatic melanoma: basic and clinical aspects. Am J Cancer Res 1 (7):913-924

Sinha R, Kim GJ, Nie S, Shin DM (2006) Nanotechnology in cancer therapeutics: bioconjugated nanoparticles for drug delivery. Molecular Cancer Therapeutics 5 (8):1909-1917. doi:10.1158/1535-7163.mct-06-0141

Skehan P, Storeng R, Scudiero D, Monks A, McMahon J, Vistica D, Warren JT, Bokesch H, Kenney S, Boyd MR (1990) New Colorimetric Cytotoxicity Assay for Anticancer-Drug Screening. Journal of the National Cancer Institute 82 (13):1107-1112. doi:10.1093/jnci/82.13.1107

Taylor U, Klein S, Petersen S, Kues W, Barcikowski S, Rath D (2010) Nonendosomal cellular uptake of ligand-free, positively charged gold nanoparticles. Cytometry A 77 (5):439-446

Tsutsumida H, Swanson BJ, Singh PK, Caffrey TC, Kitajima S, Goto M, Yonezawa S, Hollingsworth MA (2006) RNA Interference Suppression of MUC1 Reduces the Growth Rate and Metastatic Phenotype of Human Pancreatic Cancer Cells. Clinical Cancer Research 12 (10):2976-2987. doi:10.1158/1078-0432.ccr-05-1197

Vichai V, Kirtikara K (2006) Sulforhodamine B colorimetric assay for cytotoxicity screening. Nat Protoc $1(3): 1112-1116$

Wang X, Chi N, Tang X (2008) Preparation of estradiol chitosan nanoparticles for improving nasal absorption and brain targeting. Eur J Pharm Biopharm 70 (3):735-740

Yousefpour P, Atyabi F, Vasheghani-Farahani E, Movahedi AA, Dinarvand R (2011) Targeted delivery of doxorubicin-utilizing chitosan nanoparticles surface-functionalized with anti-Her2 trastuzumab. Int J Nanomedicine 6:1977-1990 


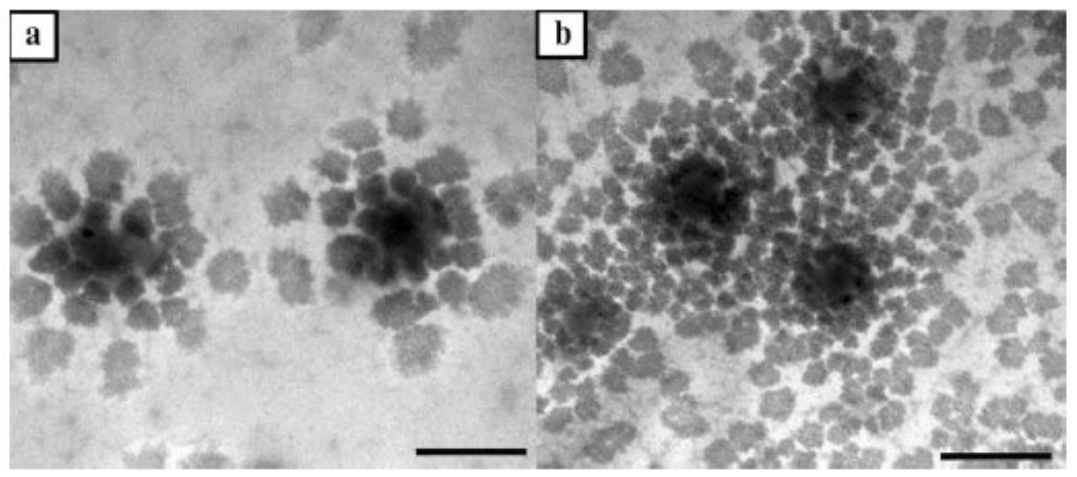

Fig. 1 Transmission electron microscope images of (a) Ch-GA-PEGAuNPs, (b) Ch-GABTZ+PEGAuNPs. Scale bar represent $200 \mathrm{~nm}$.

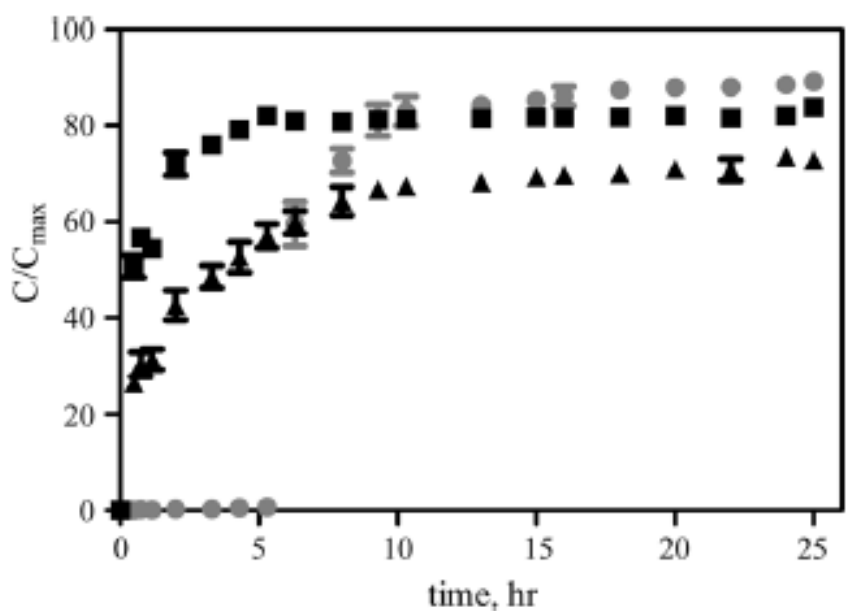

Fig. 2 Release profiles of Ch-GA-BTZ+PEGAuNPs (•), Ch-GA-BTZ NPs ( $\bullet$ ) and BTZ alone ( $\mathbf{\Delta})$ in DI water (a) and PBS 0.01 M (b). $\mathrm{C}_{\max }$ corresponds to the total amount of BTZ added. 

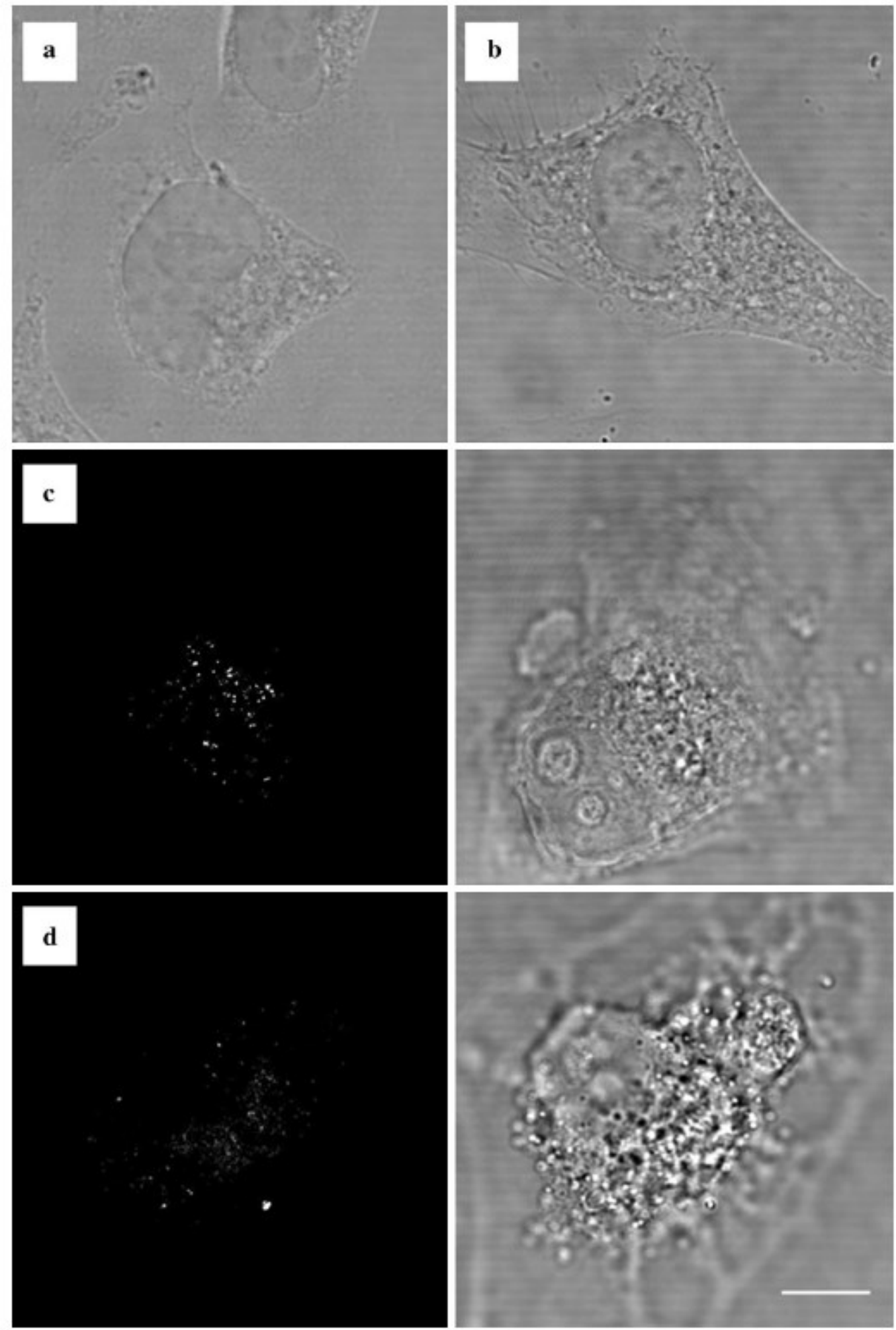

Fig. 3 Confocal reflectance and transmission images of the S2-013 (a, c) and hTERT-HPNE (b, d) cells after 48 hours incubation. The cells were incubated with Ch-GA-BTZ+PEGAuNPs nanoparticles with BTZ concentration of $100 \mathrm{nM} ;(\mathrm{a}, \mathrm{b})$ the control untreated of S2-013 and hTERT-HPNE cells, respectively. Scale bar in all images is $10 \mu \mathrm{m}$. 

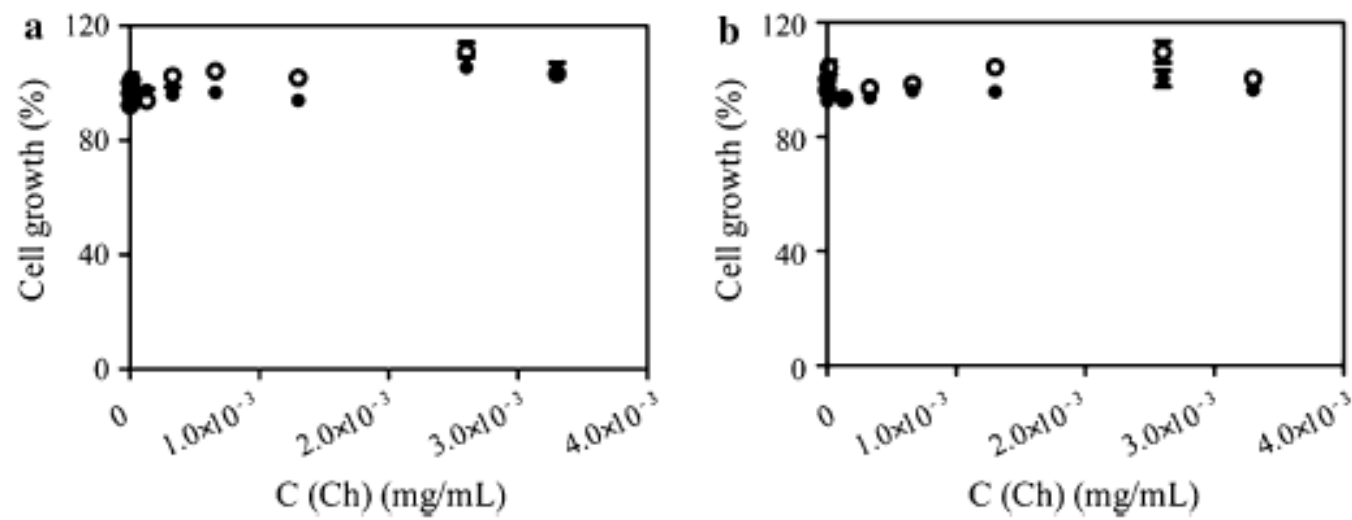

Fig. 4 Cytotoxicity induced by Ch-GA-PEGAuNPs (•) and Ch-GA NPs $(\bullet)$ at $\mathrm{R}_{\mathrm{GA} / \mathrm{Ch}}=1.2$ on S2-013 (a) and hTERT-HPNE (b) cells, by the SRB assay.
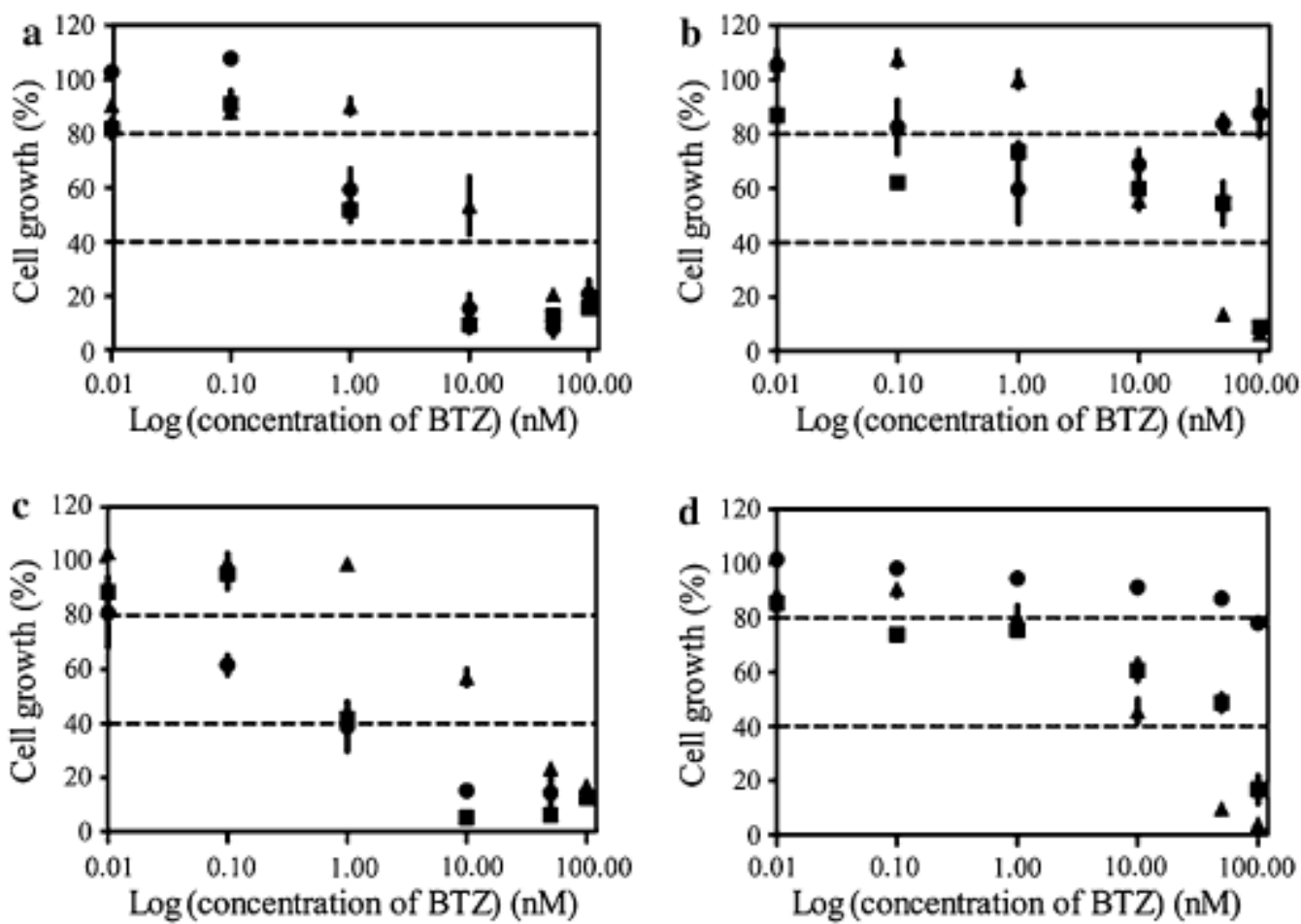

Fig. 5 Effect of the Ch-GA-BTZ+PEGAuNPs $(\bullet)$, Ch-GA-BTZ NPs $(\boldsymbol{\bullet})$ and BTZ alone $(\boldsymbol{\Delta})$ on the cell growth of S2-013 (a, c) and hTERT-HPNE (b, d) cells. (a, b) PB assay and (c, d) SRB assay. 

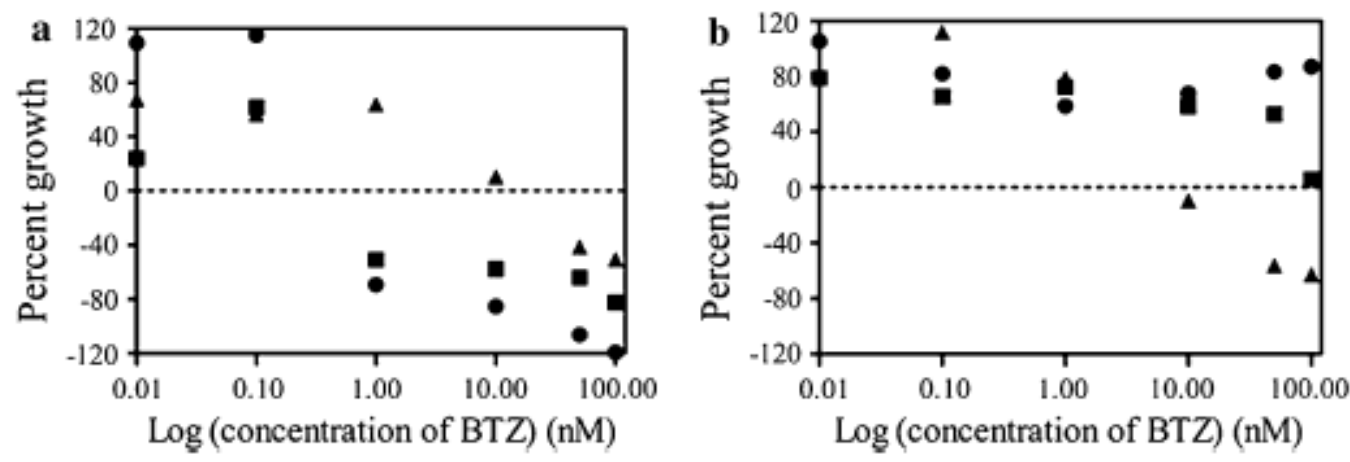

Fig. 6 Effect of the Ch-GA-BTZ+PEGAuNPs $(\bullet)$, Ch-GA-BTZ NPs $(\boldsymbol{\bullet})$ and BTZ alone $(\boldsymbol{\Delta})$ on the cell growth of S2-013 (a) and hTERT-HPNE (b) cells compared to the control, by the PB assay.

Electronic Supplementary Material caption

Online Resource 1 SEM micrographs of PEGAuNPs. Scale bar represent $200 \mathrm{~nm}$. 
Table 1 Hydrodynamic diameter, polydispersity index $(\mathrm{PdI})$, zeta potential and $\mathrm{pH}$ of nanoparticle systems with an initial concentrations of chitosan $0.4 \%$ ( $/ \mathrm{v}$ ) and a $\mathrm{R}_{\mathrm{GA} / \mathrm{Ch}}$ $=1.2 . "$

\begin{tabular}{|c|c|c|c|c|c|c|}
\hline Sample & $\begin{array}{l}\text { BTZ concentration } \\
\text { (nM) }\end{array}$ & $\begin{array}{l}\text { PEGAuNPs } \\
\text { concentration (nM) }\end{array}$ & $\begin{array}{l}\text { Hydrodynamic } \\
\text { diameter }(\mathrm{nm})\end{array}$ & PdI & $\begin{array}{l}\text { Zeta potential } \\
(\mathrm{mV})\end{array}$ & $\mathrm{pH}$ \\
\hline $\mathrm{Ch}-\mathrm{GA}$ NPs & - & - & $315 \pm 5$ & 0.3 & $39 \pm 1$ & 4.8 \\
\hline PEGAuNPs (stock solution) & - & 18.9 & $39 \pm 1$ & 0.6 & $-39 \pm 3$ & 5.3 \\
\hline $\mathrm{Ch}-\mathrm{GA}-\mathrm{PEGAuNPs}$ & - & 2 & $428 \pm 18$ & 0.3 & $23 \pm 3$ & 4.7 \\
\hline $\mathrm{Ch}-\mathrm{GA}-\mathrm{BTZ}$ NPs & 200 & - & $341 \pm 26$ & 0.1 & $30 \pm 3$ & 4.8 \\
\hline BTZ+PEGAuNPs & 200 & 2 & $41 \pm 0.3$ & 0.6 & $-13 \pm 2$ & 5.3 \\
\hline $\mathrm{Ch}-\mathrm{GA}-\mathrm{BTZ}+\mathrm{PEGAuNPs}$ & 200 & 2 & $327 \pm 73$ & 0.2 & $33 \pm 2$ & 4.6 \\
\hline
\end{tabular}

Table 2 Effect of BTZ, Ch-GA-BTZ NPs and Ch-GA-BTZ+PEGAuNPs on the growth inhibition of the pancreatic cell lines S2-013 and hTERT-HPNE. GI ${ }_{50}$ (nM) values correspond to concentration for

$50 \%$ of the maximum cell proliferation inhibition and was evaluated from the SRB assay.

\begin{tabular}{lll}
\hline Sample & $\mathrm{GI}_{50}(\mathrm{nM})$ & \\
\cline { 2 - 3 } & $\mathrm{S} 2-013$ & hTERT-HPNE \\
\hline BTZ & $1.70 \pm 0.35$ & $2.01 \pm 0.20$ \\
Ch-GA-BTZ NPs & $0.12 \pm 0.06$ & $50.02 \pm 2.73$ \\
Ch-GA-BTZ+PEGAuNPs & $0.20 \pm 0.02$ & - \\
\hline
\end{tabular}

$\mathrm{GI}_{50}(\mathrm{nM})$ values correspond to concentration for $50 \%$ of the maximum cell proliferation inhibition and was evaluated from the SRB assay 